\title{
EDITORIAL
}

\section{Do Universities Contribute to Sustainable Development?}

\author{
Marc A. Rosen ${ }^{1,2 \star}$
}

\author{
${ }^{1}$ Founding Editor-in-Chief, European Journal of Sustainable Development Research \\ ${ }^{2}$ Faculty of Engineering and Applied Science, University of Ontario Institute of Technology, 2000 Simcoe Street North, Oshawa, Ontario, L1G 0C5, CANADA \\ *Corresponding Author: marc.rosen@uoit.ca
}

Citation: Rosen, M. A. (2020). Do Universities Contribute to Sustainable Development?. European Journal of Sustainable Development Research, 4(2), em0112. https://doi.org/10.29333/ejosdr/6429

ARTICLE INFO

Published: 18 Dec. 2019

\begin{abstract}
Given the support of the global community of sustainable development, it is perhaps logical to infer that universities will be strong participants in the push to improve the sustainability of society in general, and among the leaders in efforts to achieve the United Nations Sustainable Development Goals (SDGs) for 2015-2030. To ascertain if this inference is valid, it can be instructive to examine and assess universities for their contributions to the SDGs. This has in fact already begun, with the launch of a new global university ranking of universities, aimed at measuring their contributions to the SDGs. Here we examine how universities contribute to sustainable development, and whether such rankings can motivate and drive initiatives that support sustainable development.
\end{abstract}

Keywords: sustainable development, sustainable development goals, universities, education, economic sustainability, environmental sustainability, social sustainability

\section{INTRODUCTION}

Universities contribute to society in a myriad of ways. Often this is in a manner that is supportive of societal initiatives. Given the support of the global community of sustainable development, as elucidated through the United Nations Sustainable Development Goals (SDGs) for 2015-2030, it is perhaps logical to infer that universities will be strong participants in the push to improve the sustainability of society in general, and among the leaders in efforts to achieve the SDGs.

In an effort to ascertain if this inference is valid, it can be instructive to examine and assess universities for their contributions to the SDGs. This has in fact already begun, with the launch of a new global university ranking of universities, which is aimed, at least in part, at addressing the question. The Times Higher Education, based in the United Kingdom, published in 2019 the world's first university impact ranking and in doing so measured the contributions of universities to the SDGs (Times Higher Education, n.d.). This ranking builds on broader activities of the Times Higher Education, which publishes regularly an annual World University Rankings.

Here we examine how universities contribute to sustainable development, and whether rankings like the new one cited above can motivate and drive initiatives that support sustainable development.

\section{UNITED NATIONS SUSTAINABLE DEVELOPMENT GOALS FOR 2015-2030}

The UN General Assembly approved the SDGs, along with appropriate targets and indicators, in September 2015 (United Nations, n.d.). The intent was, at least in part, to have countries use the SDGs as a framework for plans and policies.

The SDGs are the core of the UN's 2030 Agenda for Sustainable Development, a guide for addressing many of the world's greatest challenges. There are 17 SDGs (United Nations, n.d.):

1. End poverty in all its forms everywhere

2. End hunger, achieve food security and improved nutrition and promote sustainable agriculture

3. Ensure healthy lives and promote well-being for all at all ages

4. Ensure inclusive and equitable quality education and promote lifelong learning opportunities for all

5. Achieve gender equality and empower all women and girls 
6. Ensure availability and sustainable management of water and sanitation for all

7. Ensure access to affordable, reliable, sustainable and modern energy for all

8. Promote sustained, inclusive and sustainable economic growth, full and productive employment and decent work for all

9. Build resilient infrastructure, promote inclusive and sustainable industrialization and foster innovation

10. Reduce inequality within and among countries

11. Make cities and human settlements inclusive, safe, resilient and sustainable

12. Ensure sustainable consumption and production patterns

13. Take urgent action to combat climate change and its impacts

14. Conserve and sustainably use the oceans, seas and marine resources for sustainable development

15. Protect, restore and promote sustainable use of terrestrial ecosystems, sustainably manage forests, combat desertification, and halt and reverse land degradation and halt biodiversity loss

16. Promote peaceful and inclusive societies for sustainable development, provide access to justice for all and build effective, accountable and inclusive institutions at all levels

17. Strengthen the means of implementation and revitalize the global partnership for sustainable development

The SDGs recognize the three key pillars of sustainable development: economic, environmental and social, and their interface with all parts of societies. The development and approval of the SDGs has led to an increase in education, research and activity related to sustainable development. For instance, research has been carried out on issues, concepts and applications related to sustainable development (Rosen, 2018), on the sustainable development of energy, water and environment systems (Kilkis et al. 2019), into psychological processes in sustainable development (Di Fabio and Rosen, 2018), and on advances in sustainable development research (Rosen, 2019).

\section{RANKING UNIVERSITIES' CONTRIBUTIONS TO THE SDGS}

The new university ranking may provide an important measure of the contributions of universities to sustainable development, and thus could foster needed action in this area. The ranking could create a better understanding of the urgent challenges related to sustainable development, and motivate universities to act, as well as to collect data and to monitor their performance. Such actions can help establish a capacity for actions and decision-making around sustainable development.

Of course, institutions of higher education like universities traditionally have played an important role within society as significant actors in the creation and dissemination of knowledge, with or without rankings. So perhaps universities will evolve into strong contributors to sustainable development on their own. However, directly linking the SDGs and universities through a ranking could increase the level of contributions to and impact on the SDGs by universities, and make this happen more rapidly.

Determining if the new ranking actually assesses reasonably and meaningfully the contributions of universities to the SDGs is itself challenging. Most ranking systems have strengths and weaknesses, and virtually all have at least some detractors. The metrics used in rankings need to be sound and meaningful, and somewhat acceptable to all relevant stakeholders. The UN's 17 SDGs have 169 indicators and 223 targets. The methodology applied in the new ranking seeks to establish links among these and is based on a subset of this information, specifically 11 SDGs, 47 metrics and 111 targets. Universities may submit data relevant to all 11 SDGs (a minimum of four), and must include the sustainable development goal of strengthening global partnerships (SDG 17).

The methodology was developed by the publisher, including the selection of which SDGs would be assessed. This is a potential criticism. But rankings always generate criticisms, as they cannot avoid all weaknesses. Reasonable concerns are likely to be expressed by the international university community over the methodological and data limitations of global university rankings. But, despite the fact that rankings can create perhaps inappropriate incentives for institutions in decisions and actions, the ranking of university contributions to the SDGs will hopefully be meaningful and helpful.

One interesting aspect of the new ranking is that standards for participation appear to be more inclusive than those of Times Higher Education's annual world university rankings. The new impact ranking simply requires universities to be accredited by their national accreditation system, which should make most universities eligible and encourage more to participate in the ranking exercise.

Another interesting aspect of the new ranking is that, instead of focusing mainly on inputs like university expenditures on SDGs and outputs like university research publications about the SDGs, an attempt has been made to focus on impact (or outcomes) like contributions to the sustainability of communities. That shift in focus may make the rankings more relevant and representative, even though it may make the comparison more subjective.

\section{CLOSING REMARKS}

The university impact ranking may focus governments and societies at large to ponder on how universities can best help address the many complex topics linked to sustainable development, including numerous environmental, economic and social challenges. The relevance to universities of the SDGs combined with the growing interest by governments on the SDGs make this 
likely to be observed in many countries. The new ranking may promote dedicated funding for SDG-related education and research, and bolster government and public support for sustainable development and the SDGs.

Academics and others are evaluating the impact ranking. Hopefully, that will allow it to be improved and refined in the future as a means of assessing how universities contribute to sustainable development. Such scrutiny may help ensure that the ranking does not exert a detrimental effect on higher education and at the same time make the ranking more relevant to the education community, more beneficial to society broadly, and more useful to governments. Perhaps the ranking provides a response, or at least a partial one, to a question posed by this author earlier (Rosen, 2017): How can we achieve the UN Sustainable Development Goals?

\section{REFERENCES}

Di Fabio, A., \& Rosen, M. A. (2018). Opening the Black Box of Psychological Processes in the Science of Sustainable Development: A New Frontier. European Journal of Sustainable Development Research, 2(4), 47 (editorial). https://doi.org/10.20897/ejosdr/ 3933

Kilkis, S., Krajacic, G., Duic, N., Montorsi, L., Wang, Q., Rosen, M. A., \& Al-Nimr, M. A. (2019). Research Frontiers in Sustainable Development of Energy, Water and Environment Systems in a Time of Climate Crisis. Energy Conversion and Management, 199, 111938. https://doi.org/10.1016/j.enconman.2019.111938

Rosen, M. A. (2017). How Can We Achieve the UN Sustainable Development Goals? European Journal of Sustainable Development Research, 1(2), 06. https://doi.org/10.20897/ejosdr.201706

Rosen, M. A. (2018). Issues, Concepts and Applications for Sustainability. Glocalism: Journal of Culture, Politics and Innovation, 3, 121.

Rosen, M. A. (2019). Advances in Sustainable Development Research. European Journal of Sustainable Development Research, 3(2), em0085 (editorial). https://doi.org/10.29333/ejosdr/5730

Times Higher Education. University Impact Rankings (2019). Retrieved on 25 November 2019 from https://www.timeshigher education.com/rankings/impact/2019/overall\#!/page/0/length/25/sort_by/rank/sort_order/asc/cols/undefined

United Nations. Sustainable Development Goals Knowledge Platform. (n.d.). Retrieved on 25 November 2019 from https://sustainabledevelopment.un.org/ 